


\title{
ENTREDICHOS DE LA SOCIEDAD DEMOCRÁTICA COSTARRICENSE: CIENCIA FICCIÓN Y POLÍTICA
}

\author{
BANS IN COSTA RICAN DEMOCRATIC SOCIETY: SCIENCE FICTION \\ AND POLITICS
}

\author{
Geaninni Ruiz, Ulloa
}

\begin{abstract}
RESUMEN
Este artículo plantea que el texto de ciencia ficción se produce a partir de una interacción con su contexto social, contradiciéndose así las consabidas definiciones de la ciencia ficción como un género evasivo y de entretenimiento. Asimismo, el carácter crítico de la ciencia ficción se ilustra por medio de dos cuentos costarricenses, los cuales por medio de la utopía y la distopía problematizan ciertos aspectos de la sociedad democrática costarricense.

Palabras clave: ciencia ficción, sociedad, utopía, distopía
\end{abstract}

\begin{abstract}
This article proposes that science fiction texts are produced based on an interaction with the social context, contradicting traditional definitions about science fiction as an evasive and advertising genre. Also, the critical aspect of science fiction is illustrated with two Costa Rican short stories that, by using dystopia and utopia, show some dubious aspects of the Costa Rican democratic society. Key words: science fiction, society, utopia, dystopia.
\end{abstract}

\section{Introducción}

Cuando hablamos de ciencia ficción comúnmente pensamos en: robots, naves espaciales, guerras intergalácticas y una centena de aparatos inverosímiles; sin embargo, la ciencia ficción, no sólo es ciencia ficcionada, ni ficción científica, pues como categoría que define un género, es sumamente limitante o estrictamente insuficiente.

El término ciencia ficción fue acuñado por Hugo Gernsback en 1921, por motivo de la publicación de un conjunto de relatos de viajes fantásticos en Amazing Stories (1926). No obstante, desde el comienzo este término generó problemas, debido a que no se tenía claro qué clase de relatos podían ser categorizados como tales. Por ejemplo, algunos textos planteaban

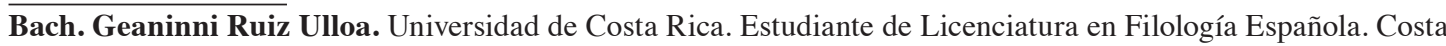
Rica.

Correo electrónico: geaninniruiz@gmail.com

Recepción: 06- 02- 2014

Aceptación: 15- 03- 2014 
una nueva configuración de la sociedad en donde no necesariamente aparecían robots o elementos tecnicistas. Lo cierto es que el término se popularizó y dentro de sí, empezaron a confluir una serie de subgéneros, que le han proporcionado gran vitalidad discursiva.

En esta oportunidad, planteamos analizar el carácter crítico de la ciencia ficción, evidenciando su relación con lo social, a partir del uso de la utopía y la distopía en los cuentos "Un día en la vida de Isidro Sevilla" de Pablo Rojas (1996) y "Febrero 2034" de Iván Molina-Jiménez (2003).

\section{2. ¿Definición(es) sobre Ciencia Ficción?}

El crítico español, Moreno (2008), considera que para entender la propuesta de la ciencia ficción es pertinente conocer el contexto en el que nace el género. Este, para el profesor Moreno-Serrano, corresponde al periodo del positivismo. Dentro de esta corriente filosófica, la realidad se entiende como aquello que es comprobable, imponiéndose así a toda percepción subjetiva (como los deseos y las opiniones), es decir, la realidad se piensa como algo palpable, que se puede resolver de forma empírica.

Con el afán de aproximarnos a una definición del género, Moreno (2008) plantea algunas definiciones tipificadas -y empobrecedoras- sobre cómo se ha tratado la ciencia ficción, a saber:

a. Únicamente como los relatos que tratan temáticas relacionadas con la ciencia que se sitúan en un tiempo futuro. En ese sentido, es considerada como visionaria o adelantada al desarrollo científico del momento (naturaleza profética).

b. Como literatura meramente juvenil.

c. Como un género que conduce a la evasión, al crear mundos inverosímiles y aventuras.

En nuestro caso, partimos de la relación existente entre la ciencia ficción y la literatura fantástica, pues ambas comparten un elemento: la realidad. Por un lado, la literatura fantástica, por medio de una transgresión que irrumpe en la realidad, pone en duda que esta sea tan sólida y estable como creemos; por otro lado, la ciencia ficción parte del hecho de no-problematizar la realidad, más bien,se acepta esta tal como es. De esta forma, menciona Moreno (2008, p. 77), "Lo que problematiza es la lectura que hacemos de la realidad y todo lo que hemos construido a partir de dicha lectura errónea. La ciencia ficción pretende ir, por tanto, al fondo del problema cultural". Más adelante, afirma: "La ciencia ficción no metaforiza la realidad, sino todo lo contrario. La ciencia ficción dice: esto no es la realidad. Insiste mucho en recordárnoslo. Porque lo que hace es usar ese elemento para desarrollarlo, hiperbolizarlo hacia otro punto alejado de la realidad" (Moreno, 2008, p. 80). En otras palabras, la ciencia ficción se presenta como un constructo retórico que permite repensar la realidad, al externalizarla en una forma totalmente distinta, produciéndose así que el efecto de extrañamiento surja a partir de ese otro mundo que utiliza referentes muy similares a los nuestros.

El replanteamiento cultural de los textos de ciencia ficción puede abarcar aspectos variopintos de la realidad. En este caso en particular, nos interesa referirnos a la relación entre la ciencia ficción y la política (sistema de gobierno), la cual abordaremos a partir del concepto de utopía y posteriormente, el de distopía. López-Keller (1991, p. 23) afirma que la utopía "representa, pues, un sueño de perfección social", que varía según la sociedad en que 
se conciba, siguiendo esa misma línea, Tomás Moro (2009) la define como el no-lugar. La utopía, discursivamente, ha desempeñado funciones retóricas principalmente como: a) servir de denuncia, al realizar un análisis minucioso de las prácticas y costumbres de una sociedad o b) aumentar la confianza en las posibilidades humanas en su afán por el progreso.

Para López-Keller (1991, p. 15), la utopía del siglo XX es la pérdida de la fe en el Progreso, la cual también es llamada la distopía o utopía negativa, la cual se caracteriza fundamentalmente por su aspecto de denuncia ante los posibles o hipotéticos desarrollos perniciosos de la sociedad actual. Asimismo, Álvaro Lázaro, analizando la novela de England, England de Julien Barnes, menciona lo siguiente:

\begin{abstract}
Más que un sueño maravilloso, la distopía nos ofrece una pesadilla. Es una visión premonitoria con la que el autor pretende lograr un doble objetivo: por un lado, advertir al lector de los peligros inherentes en el pensamiento utópico y, por otro, censurar los males de la sociedad, sus individuos o instituciones. (Lázaro, 2002, p. 210)
\end{abstract}

Tanto la utopía y la distopía replantean, por medio de la tematización de sociedades futuristas, un cuestionamiento sobre la estructuración de las formas de organización social. Unido a lo anterior, Bajtin evidencia que la relación entre el desarrollo del arte y la sociedad se realiza dentro de un proceso semiosis, afirmando de esta manera que "la literatura es una parte inalienable de la cultura y no puede ser comprendida fuera del contexto" (2008, p. 347).

\title{
3. Ciencia ficción costarricense
}

\subsection{Utopía sin democracia}

El cuento "Un día en la vida de Isidro Sevilla" (1996) narra a detalle el itinerario de Isidro, un costarricense de 42 años que desempeña el puesto de elector. Este cargo consiste en ser el representante internacional de Costa Rica ante las demás naciones, debido a que en el 2040 -momento en que se sitúa la narración- las figuras del presidente, embajador y demás representantes del poder ejecutivo, han perdido toda utilidad. El texto comienza anunciándonos la pronta visita de los electores de Chile y Argentina, quienes han solicitado una urgente reunión con Isidro, ya que se debe decidir el futuro de la comercialización de los cristales (principales contenedores de información) puesto que en el mundo de Isidro, la información es símbolo de poder. Los electores sudamericanos desean obtener el apoyo de Costa Rica (pues el país es uno de los mayores exportadores de energía limpia) en una posible coalición en contra de Brasil. Además, el cuento también nos presenta los detalles de las distintas actividades que rodean la vida de las personas de en esa sociedad (tiempo libre y pasatiempos, educación, medios de transporte, entre otros).

Conforme avanza la lectura del texto, se vuelve cada vez más notorio que el sistema de gobierno democrático pierde su funcionalidad, no sólo en el ámbito nacional, sino también internacional. De hecho, este es sustituido por una forma de organización mucho más global y coarticulada, en la que cada país tiene un representante (un elector), creando así una confederación internacional de electores. En ese sentido, la democracia es vista como un gobierno inestable y podríamos llamarlo "localista", el cual impide un verdadero progreso mundial.

Los presidentes habían perdido todo sentido de representatividad internacional desde los años 10 . Ante esto fue necesario que los organismos de carácter mundial solicitaran el nombramiento de electores, los cuales tenían un código especial de ingreso a los sistemas de elección de funcionarios, de distribución presupuestario, de control de armamentos y de acciones de socorro o emergencia mundiales. (Rojas, 1996, p. 19) 
La sociedad costarricense en la que vive Isidro ha aprovechado la tecnología para lograr un mejoramiento económico, político, ambiental y social. Costa Rica, por ejemplo, se destaca por ser un exportador nato de energía limpia (es decir, energía eólica, hídrica y geotérmica). Además, sobresale como un país que ha ido a la vanguardia en la implementación de políticas ambientales, ya que en ese mundo futurista se ha logrado potencializar el uso de los recursos energéticos por medio de nuevos aparatos científicos, tal es el caso de los superacumuladores: "Ya en los años 20 la energía se almacenaba en pequeños superacumuladores y la electricidad se exportaba en cajas de energía, que duraban cargadas hasta cinco años" (Rojas, 1996, p. 21).

En el aspecto social, se busca la integración del ser humano ante las distintas culturas que habitan en el planeta. De ahí que la visión del trabajo se conciba como una actividad de satisfacción humana:

\footnotetext{
En los años treinta se habían difundido en varias regiones del mundo las teorías del desarrollo humano integral. Esto implicaba que los trabajos deberían tener tres etapas. Una de esfuerzo físico, otra de esfuerzo intelectual y una tercera vocación espiritual. Así también los tiempos de ocio debían dividir en descanso espiritual, descanso físico y descanso intelectual. (Rojas, 1996, p. 19)
}

La sociedad planteada por el texto ha alcanzado a través de avances tecnológicos y un progresivo desarrollo que no ha olvidado la figura del ser humano como un ente integral. Lo interesante de esta sociedad utopista es que no cae en el totalitarismo ciego que regiría todos los niveles de la vida de los personajes, como sucede en muchos textos que plantean sociedades utópicas, pues para poder existir en perfecta comunión, eliminan la voluntad del individuo, apelando a cierto determinismo.

\subsection{Distopía: el fin de la democracia}

El cuento "Febrero 2034" (2003), nos relata el comienzo de un día de Luis Dobles, quien es despertado por Matilde -su asistente robot- la cual le indica precisamente que hoy se llevarán a cabo las elecciones presidenciales. No obstante, Luis se muestra indiferente ante este hecho y, a partir de ese deseo de evasión, alude las razones por las que no quiere votar. El texto, utilizando una analepsis, explica que desde hace más de veinte años se ha venido desatando una "epidemia de suicidios", precisamente, el día de las elecciones, pues los ciudadanos prefieren suicidarse antes que votar.

Extra-textualmente, dentro del realidad nacional que nos compete, desde finales del siglo XX y principios del XXI, la democracia costarricense se debate entre la necesidad de una nueva estructuración interna, a raíz de nuevas necesidades de sus habitantes (proceso de modernización e integración mundial), y la erosión de sus instituyentes como legitimadores del poder (partidos políticos, candidatos, participación ciudadana).

El politólogo Mora-Alfaro (2010) considera que la democracia costarricense se encuentra en un punto decisivo, en el que debe entrar en un proceso de revisión para poder enfrentar los cambios sociales, económicos y políticos necesarios, que viene arrastrando desde los ochenta ante el cambio de paradigma del estado benefactor a otro con miramientos neoliberales. Un ejemplo tangible sobre el descrédito del sistema democrático costarricense -como la mejor forma de gobierno- lo representan los crecientes números en el porcentaje de abstencionismo que se registran desde 1998 hasta la elección de 2006.

En "Febrero 2034", el panorama político parece enajenar por completo al ciudadano, a pesar de los avances tecnológicos que se mencionan, como la virtulización del proceso de 
votación, no se ha logrado superar la corrupción y la malversación de los fondos públicos. El texto se encuentra así inscrito en tono satírico, pues se lleva al máximo la ridiculización del sistema democrático costarricense. Su sentido de criticidad no deja abierta la posibilidad de un empoderamiento social por parte de los ciudadanos, quienes eventualmente podrían acabar con ese círculo vicioso, sin embargo, estos son gobernados por dictámenes de cuantos fantoches.

El creciente grado de corrupción de la clase política y su doble discurso, generalmente, vacío y publicitario; parecen haber degenerado el principio democrático de la libre elección de las mayorías, pues si los candidatos dejan de representar a sus ciudadanos. Las olas de suicidios se desatan por la muerte de un viejo, él cual, dirigiéndose a la Plaza de Cultura, "se quitó el sombrero, escupió y dijo, este es mi voto" (Molina-Jiménez, 2003, p. 11) pegándose un tiro al momento. Esta muerte que pasa inadvertida por los medios de comunicación, resulta ser el detonante para que en las próximas elecciones y así, progresivamente, aumenten los suicidios. Como se ilustra en el texto a continuación:

\footnotetext{
La sorpresa vino cuatro años después. El domingo de los comicios, veinte personas se mataron porque no tenían por quién votar: diez emplearon arma de fuego, cinco se defenestraron, uno se ahorcó con una soga fabricada con las banderas de todos los partidos, otro se envenenó al comerse los futuros programas de gobierno y tres, con sus cuerpos desnudos empapelados con propaganda electoral, se prendieron fuego frente del Tribunal Supremo de Elecciones. (Molina-Jiménez, 2003, p. 11)
}

La clase política, al ver el creciente aumento en la cifra de los suicidios, decide implementar medidas para disminuir esta situación -tal vez podríamos pensar en una posible regeneración por parte de los políticos al observar la creciente molestia de los ciudadanos- sin embargo, el gobierno se limita a lanzar una campaña preventiva en 2029 que llevaba el lema “Sea patriota ¡Vote! ¡No se mate!”, el cual, obviamente no tuvo los resultados esperados.

No obstante, en medio del paroxismo social, nunca falta alguien que con un poco de ingenio capitalista aproveche la situación, así es como en 2030 los intelectuales Miguel Ángel y José María Ruggiero publican una obra titulada “¿Cómo suicidarse en un día de elecciones? Consejos prácticos para elegir el lugar, la hora y el medio" (Molina-Jiménez, 2003, p. 13). Lo absurdo de los acontecimientos provoca que se mantenga una visión sumamente pesimista sobre el progreso real de la sociedad costarricense, pues hasta la muerte de los votantes es vista como negocio, pues una empresa funeraria transnacional llamada Muerte feliz, la cual "por un módico diez por ciento adicional, ofrecía a los eventuales suicidas sepultarlos 24 horas después del fallecimiento" (Molina-Jiménez, 2003, p. 18).

Es por medio de instancias internacionales que se evidencia la problemática de los suicidios electorales, ya que gracias a la investigación de los doctores Paul Palmerson y Edward Lequc, se logra determinar la causa que provoca los suicidios una rara enfermedad llamada: asfixia electoral, la cual se explica como "la autodestrucción de los ticos obedecía al creciente deterioro moral de su clase política" (Molina-Jiménez, 2003, p. 12). La ONU se encarga de dictar a la clase política un ultimátum pues, si no baja la tasa de suicidios, el país podría ser intervenido y de esta forma, esta podría ser destituida.

Esta sociedad distópica no plantea alternativas para regenerar su funcionamiento. De hecho, la sátira hacia la sociedad costarricense actual es contunde como lo demuestra el siguiente fragmento, "con la vertiginosa privatización del INS, ICE y la CCSS, y con la subasta de las universidades públicas (compradas a plazos y sin prima por colleges de Miami de quinta categoría)" (Molina-Jiménez, 2003, p. 19). De ahí que se utilicen referentes que apelen a la realidad inmediata de la sociedad costarricense, jugando con nombres de políticos e intelectuales, como de instituciones. 


\section{Conclusiones}

El carácter pesimista e irónico de Molina-Jiménez sobre el futuro del sistema democrático costarricense se contrapone a una visión positiva del futuro en donde, si bien es cierto no existe el régimen democrático, este no es motivo de molestia por parte de sus ciudadanos, pues al contrario, las ventajas de esta integración mundial son mucho más beneficiosas. En ese sentido, el cuento de Pablo Rojas nos remite a una sociedad futurista-progresista, en la cual hay un mejoramiento del ser humano y su desarrollo integral, en otras palabras, una sociedad utópica que ha alcanzado tal estado a partir del cambio del paradigma democrático.

En contraposición, en el cuento de Molina-Jiménez, el descrédito y el pesimismo ante un sistema de gobierno democrático degenerado conduce a sus habitantes a preferir la muerte antes que la enajenación social en que se vive, como termina sucediéndole a Luis Dobles, que un minuto antes de que se cerrasen las urnas, decide suicidarse desde la ventana de su apartamento.

Ambas visiones nos permiten reflexionar sobre el carácter crítico que aporta la ciencia ficción como género, y de esta manera, desmiente aquella presunción que la considera como sumamente evasiva y de entretenimiento. Aún más, en la coyuntura política en que nos encontramos, los dos cuentos manifiestan el descrédito ante el sistema político costarricense.

Así, por medio de la utopía y de la distopía, podemos replantearnos cómo se configura nuestra sociedad, pues ya sea con naves espaciales o robots, la necesidad de vivir en una sociedad igualitaria y justa sigue siendo un deseo de todos.

\section{Bibliografía}

Moreno, F.Á. (Eds.). (2008). La ficción prospectiva: Propuesta para una delimitación del género de la Ciencia Ficción. Por F.Á. Moreno y T. López-Pellisa (Eds.). Ensayos sobre ciencia ficción y literatura fantástica. [Versión digital]. (65-93). http://www.academia. edu/ [Consulta 23 de agosto de 2013].

Bajtin, M. (2008). Estética de la creación verbal. Editorial: Siglo XXI.

Lázaro, A. (2002). Tradición distópica en England, England de Julian Barnes. [pdf]. Por P. AbadGarcía, J.M. Barrio-Marco y J.M. Ruiz-Ruiz (Eds.). Estudios de literatura en lengua inglesa del siglo XX. (Vol. 6). (195-202). http://dspace.uah.es/ [Consulta 23 de agosto de 2013].

López-Keller, E. (1991). Distopía otro final de la utopía. Reis: Revista Española de Investigaciones Sociológicas. 55, 7-23. DOI: 10.2307/40183538.

Molina-Jiménez, I. (2003). La miel de los mudos: y otros cuentos ticos de ciencia ficción. San José: Editorama.

Mora-Alfaro, J. (2010). La democracia costarricense en el siglo XXI: desafíos y esperanzas. En Primer ideario costarricense del Siglo XXI. (75-106). Heredia: Programa de Publicaciones e Impresiones de la Universidad Nacional.

Moro, T. (2009). Utopía. Buenos Aires: Colihue Clásica.

Rojas, P. (1996). Un día en la vida de Isidro Sevilla. Por R. Sasso (Ed.). C.R 2040. (13-24). San José: EUNED. 